\title{
Antimicrobial Activity of Citronella Essential Oil on Antimicrobial Drug Resistant Bacteria from Veterinary Clinical Cases
}

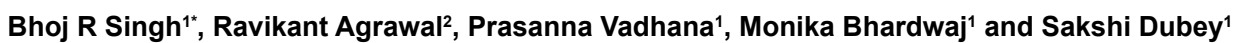 \\ ${ }^{1}$ Division of Epidemiology, ICAR-Indian Veterinary Research Institute, Izatnagar, Uttar Pradesh, India \\ ${ }^{2}$ Division of Livestock Products Technology, ICAR-Indian Veterinary Research Institute, Izatnagar, Uttar Pradesh, India
}

\begin{abstract}
Study on citronella essential oil (CEO) sensitivity of 217 microbial strains of 65 species, isolated from animals with different disease conditions, revealed that citronella oil inhibited growth of only $10.6 \%$ strains. CEO inhibited Candida but of no Aspergillus strain. CEO inhibited 22 of 211 bacterial strains. Ampicillin was the least effective antibiotic but inhibited $41.2 \%$ bacterial strains. Gram positive bacteria (GPBs) were 4.5 more sensitive $(p, 0.0006)$ to CEO than Gram negative bacteria (GNBs). More GNB strains ( $p, 0.02$ ) were multi-drug resistant (MDR) type than GPB strains. Probability of CEO resistant was high in MDR strains (p, 0.006). Most of the Brucella abortus strains had MDR (83.3\%). Strains of swamp buffalo origin were more $(p, 0.08)$ commonly CEO $(96.6 \%)$ resistant than strains of dog $(81.3 \%)$ origin. MDR was the maximum in abortion associated $(51.2 \%)$ strains and minimum in diarrhoea associated strains $(25 \%)$. The study indicated that CEO is not an effective antimicrobial against veterinary clinical isolates. Antimicrobial drug resistance and CEO resistance patterns of bacteria were dependent on type of pathogen, its source and association with disease in animals and may be important for deciding an effective antimicrobial therapy.
\end{abstract}

Keywords: Citronella oil; Antimicrobial; Antibacterial; MDR; Brucella; Klebsiella; Salmonella

\section{Introduction}

Citronella essential oil (CEO) is extracted from an herbaceous grass like tropical plant, Cymbopogon nardus, through steam distillation. Though it contains more than 22 compounds, geraniol, trans-citral, cis-citral, geranyl acetate, citronellal (6-octenal, 3, 7-dimethyl) and citronellol are the major constituents [1]. Citronellal alone constitutes about $29.6 \%$ of CEO [2]. Its use started long back as mosquito repellent [3]. CEO had immunomodulatory effect [4]. Besides, it has also been reported antifungal and antimicrobial $[1,2,5-8]$. It has been used as an alternative to commercial antibiotics in aquaculture [2] and also in aromatherapy for acne cures [9]. As an antimicrobial, citronella essential oil (CEO) has been shown to be inhibitory for about $50 \%$ strains of bacteria and fungi [7].

Citronella oil though effective against several species of bacteria is not equally active against all of them, minimum inhibitory concentration (MIC) varied significantly for different pathogens $(0.12 \%$ to $>2 \%, \mathrm{v} / \mathrm{v})$, minimum for Staphylococcus aureus and Candida albicans and more for Salmonella, Serratia and Pseudomonas strains [6]. In another study [10] on Propionibacterium acnes, CEO had MIC equivalent to $0.125 \%(\mathrm{v} / \mathrm{v})$ against all 5 strains tested. Recently [2], CEO has been reported inhibitory to 36 microbes of aquatic origin with an MIC ranging between $0.244 \mu \mathrm{g} / \mathrm{ml}$ for Pseudomonas and Salmonella to $0.977 \mu \mathrm{g} / \mathrm{ml}$ for Edwardsiella tarda and Aeromonas strains, which is much lower than earlier reports [6] for similar strains. CEO was found effective against $S$. aureus, Bacillus subtilis, Proteus vulgaris and Pseudomonas aeruginosa but could not inhibit Escherichia coli and Klebsiella pneumoniae strains and had MIC $>12.8 \mathrm{mg} / \mathrm{ml}$ [11]. The wide variation in MIC of CEO for different strains of bacteria of different as well as of the same species and of different origin necessitated reexamination of antimicrobial activity of CEO on bigger population of microbes. Therefore, this study was planned to examine the inhibitory effect of CEO on strains of wide variety of microbes of different origin using the same scale of testing. The study also attempted to establish association between conventional antimicrobial drug resistance and sensitivity to CEO. The study included 217 strains of microbes belonging to 65 species of 34 genera isolated from different disease conditions in animals and human beings.

\section{Materials and Methods}

\section{Bacterial isolates}

A total of 217 microbial strains including 211 bacterial strains, 5 Aspergillus and one Candida albicans isolates. Microbes in the study were either isolated from animals and their environment (211) or were reference (6) strains available in the laboratory were tested. All strains were revived and checked for purity on blood agar using standard microbiological methods [12,13]. Bacterial isolates (211) from more than 13 sources included in the study belonged to 62 species of 32 genera (Tables 1 and 2). Slants of pure cultures were stored on blood agar (BBL, Difco) until used for sensitivity assays.

\section{Sensitivity to CEO}

Six reference bacterial strains, 211 microbial cultures from different sources were tested in duplicate for their sensitivity to CEO $(2 \mu \mathrm{L} /$ disc $)$ using disc diffusion method [14] on Mueller Hinton (MH) agar (BD $\mathrm{BBL}$ and Difco). All strains were tested for sensitivity on $\mathrm{MH}$ agar but Moraxella, Streptococcus, Brucella and Pasteurella strains were tested on brain heart infusion (BHI) agar (BD BBL and Difco) instead of $\mathrm{MH}$ agar due to their fastidious nature [15]. All strains were tested at $37^{\circ} \mathrm{C}$ under aerobic incubation, however, Brucella inoculated plates were incubated under $5 \% \mathrm{CO}_{2}$ enriched environment. The $\mathrm{CEO}$ discs were prepared to contain $2 \mu \mathrm{L}$ of CEO in each disc as described earlier [14].

*Corresponding authors: Dr. Bhoj R Singh, Act. Head of Division of Epidemiology, ICAR- Indian Veterinary Research Institute, Izatnagar-243 122, Uttar Pradesh, India, Tel: +918449033222; E-mail: brs1762@gmail.com

Received October 14, 2015; Accepted November 06, 2015; Published November 12, 2015

Citation: Singh BR, Agrawal R, Prasanna Vadhana, Bhardwaj M, Dubey S (2015) Antimicrobial Activity of Citronella Essential Oil on Antimicrobial Drug Resistant Bacteria from Veterinary Clinical Cases. Clin Med Biochem Open Access 1: 106. doi:10.4172/2471-2663.1000106

Copyright: () 2015 Singh BR, et al. This is an open-access article distributed under the terms of the Creative Commons Attribution License, which permits unrestricted use, distribution, and reproduction in any medium, provided the original author and source are credited. 
Citation: Singh BR, Agrawal R, Prasanna Vadhana, Bhardwaj M, Dubey S (2015) Antimicrobial Activity of Citronella Essential Oil on Antimicrobial Drug Resistant Bacteria from Veterinary Clinical Cases. Clin Med Biochem Open Access 1: 106. doi:10.4172/2471-2663.1000106

Page 2 of 9

\begin{tabular}{|c|c|c|c|c|c|c|c|c|c|c|c|}
\hline \multirow{2}{*}{ Microbes (Number of strains tested) } & \multicolumn{11}{|c|}{ Number of strains resistant to } \\
\hline & CEO & $\mathbf{T}$ & G & Nf & Co & Cf & C & $A z$ & Ct & A & MD \\
\hline Acromobacter xylosoxidans (1) & 1 & 0 & 0 & 0 & 0 & 0 & 0 & 0 & 0 & 0 & 0 \\
\hline Acinetobacter Iwoffii (1) & 1 & 0 & 1 & 1 & 1 & 0 & 0 & 1 & 1 & 1 & 1 \\
\hline Actinobacillus seminis (1) & 0 & 0 & 0 & 0 & 1 & 0 & 0 & 0 & 0 & 0 & 0 \\
\hline Actinobacillus spp. (1) & 1 & 1 & 1 & 1 & 1 & 1 & 1 & 1 & 1 & 1 & 1 \\
\hline Aerococcus spp. (2) & 1 & 0 & 0 & 1 & 0 & 0 & 0 & 0 & 0 & 0 & 0 \\
\hline Aeromonas caviae (1) & 1 & 0 & 0 & 0 & 0 & 0 & 0 & 0 & 0 & 1 & 0 \\
\hline Aeromonas eucranophila (1) & 1 & 0 & 0 & 0 & 0 & 0 & 0 & 0 & 0 & 1 & 0 \\
\hline Aeromonas media (3) & 2 & 1 & 0 & 0 & 1 & 0 & 1 & 0 & 0 & 3 & 1 \\
\hline Aeromonas salmonicida ssp. salmonicida (1) & 1 & 0 & 0 & 0 & 0 & 0 & 0 & 0 & 0 & 0 & 0 \\
\hline Alkaligenes faecalis (2) & 2 & 1 & 0 & 0 & 0 & 1 & 0 & 0 & 0 & 1 & 1 \\
\hline Alkaligenes denitrificans (1) & 1 & 0 & 0 & 0 & 0 & 1 & 0 & 0 & 0 & 1 & 0 \\
\hline Aspergillus niger (1) & 1 & 1 & 1 & 1 & 1 & 1 & 1 & 1 & 1 & 1 & 1 \\
\hline Aspergillums flavus (4) & 4 & 4 & 4 & 4 & 4 & 4 & 4 & 4 & 4 & 4 & 4 \\
\hline Bacillus licheniformis (1) & 1 & 0 & 0 & 0 & 1 & 0 & 0 & 0 & 0 & 0 & 0 \\
\hline Bacillus spp. (5) & 3 & 0 & 0 & 0 & 1 & 0 & 0 & 0 & 1 & 1 & 0 \\
\hline Brucella abortus (12) & 12 & 2 & 0 & 3 & 12 & 7 & 0 & 10 & 1 & 11 & 10 \\
\hline Candida albicans (1) & 0 & 1 & 1 & 1 & 1 & 1 & 1 & 1 & 1 & 1 & 1 \\
\hline Citrobacter amalonaticus (1) & 1 & 0 & 0 & 0 & 0 & 0 & 0 & 0 & 0 & 1 & 0 \\
\hline Citrobacter freundii (1) & 1 & 0 & 0 & 0 & 0 & 0 & 0 & 0 & 1 & 0 & 0 \\
\hline Edwardsiella hoshniae (1) & 1 & 0 & 1 & 0 & 0 & 0 & 0 & 1 & 0 & 1 & 1 \\
\hline Edwardsiella tarda (2) & 2 & 1 & 0 & 0 & 1 & 0 & 0 & 0 & 0 & 2 & 1 \\
\hline Enterobacter agglomerans (20) & 19 & 3 & 0 & 10 & 10 & 2 & 5 & 0 & 5 & 16 & 8 \\
\hline Enterobacter amnigenus bio group I (1) & 1 & 0 & 0 & 0 & 0 & 0 & 0 & 0 & 0 & 1 & 0 \\
\hline Enterococcus spp. (6) & 6 & 0 & 0 & 2 & 2 & 0 & 1 & 0 & 0 & 1 & 1 \\
\hline Erwinia ananas (2) & 1 & 1 & 0 & 1 & 0 & 0 & 0 & 0 & 0 & 1 & 0 \\
\hline Erwinia cyperipedii (1) & 1 & 1 & 0 & 1 & 1 & 1 & 0 & 1 & 0 & 1 & 1 \\
\hline Escherichia coli (45) & 43 & 27 & 3 & 4 & 18 & 19 & 7 & 8 & 11 & 31 & 23 \\
\hline Hafnia alvei (1) & 1 & 1 & 0 & 1 & 0 & 0 & 0 & 0 & 0 & 1 & 1 \\
\hline Klebsiella pneumoniae (16) & 16 & 6 & 0 & 6 & 4 & 1 & 1 & 4 & 3 & 16 & 6 \\
\hline Kluyvera crocrescens (1) & 1 & 0 & 0 & 0 & 0 & 0 & 0 & 0 & 0 & 0 & 0 \\
\hline Kluyvera ascorbata (1) & 1 & 0 & 0 & 0 & 0 & 0 & 0 & 0 & 0 & 0 & 0 \\
\hline Listeria Monocytogenes (1) & 0 & 0 & 0 & 0 & 0 & 0 & 0 & 0 & 0 & 0 & 0 \\
\hline Micrococcus spp. (2) & 2 & 0 & 0 & 0 & 1 & 0 & 0 & 0 & 1 & 1 & 1 \\
\hline Moraxella osloensis (2) & 1 & 0 & 0 & 0 & 1 & 0 & 0 & 0 & 0 & 0 & 0 \\
\hline Morganella morganii (1) & 1 & 0 & 0 & 1 & 1 & 0 & 0 & 1 & 0 & 1 & 1 \\
\hline Pasteurella multocida B (2) & 1 & 0 & 0 & 0 & 0 & 0 & 0 & 0 & 0 & 0 & 0 \\
\hline Pasteurella langaensis (1) & 0 & 0 & 0 & 1 & 0 & 0 & 0 & 0 & 0 & 0 & 0 \\
\hline Pasteurella multocida D (1) & 1 & 0 & 0 & 0 & 0 & 0 & 0 & 0 & 0 & 0 & 0 \\
\hline Pasteurella pneumotropica (2) & 2 & 0 & 0 & 0 & 0 & 0 & 2 & 0 & 0 & 0 & 0 \\
\hline Pediococcus spp. (1) & 1 & 0 & 0 & 0 & 0 & 0 & 0 & 0 & 0 & 0 & 0 \\
\hline
\end{tabular}


Citation: Singh BR, Agrawal R, Prasanna Vadhana, Bhardwaj M, Dubey S (2015) Antimicrobial Activity of Citronella Essential Oil on Antimicrobial Drug Resistant Bacteria from Veterinary Clinical Cases. Clin Med Biochem Open Access 1: 106. doi:10.4172/2471-2663.1000106

Page 3 of 9

\begin{tabular}{|c|c|c|c|c|c|c|c|c|c|c|c|}
\hline Pragia fontium (2) & 2 & 1 & 0 & 1 & 0 & 0 & 0 & 1 & 0 & 0 & 0 \\
\hline Proteus mirabilis (4) & 4 & 4 & 0 & 2 & 4 & 1 & 1 & 3 & 4 & 2 & 4 \\
\hline Proteus penneri (2) & 2 & 1 & 0 & 1 & 1 & 0 & 0 & 1 & 0 & 1 & 1 \\
\hline Pseudomonas aeruginosa (8) & 8 & 3 & 1 & 5 & 5 & 1 & 3 & 2 & 4 & 6 & 5 \\
\hline Pseudomonas pseudoalcaligenes (2) & 2 & 1 & 0 & 1 & 1 & 0 & 1 & 1 & 0 & 2 & 1 \\
\hline Pseudomonas testosteronii (2) & 2 & 1 & 0 & 1 & 1 & 0 & 1 & 1 & 0 & 2 & 1 \\
\hline Pseudomonas vesicularis (1) & 0 & 1 & 0 & 0 & 1 & 0 & 0 & 0 & 0 & 0 & 0 \\
\hline Raoultella terrigena (4) & 4 & 1 & 1 & 2 & 3 & 1 & 0 & 2 & 1 & 4 & 2 \\
\hline Salmonella Kentucky (2) & 2 & 2 & 0 & 0 & 0 & 2 & 0 & 0 & 0 & 2 & 2 \\
\hline Salmonella Adelaide (2) & 2 & 0 & 0 & 0 & 0 & 0 & 0 & 0 & 0 & 0 & 0 \\
\hline Sphingomonas echinoides (2) & 2 & 0 & 0 & 1 & 0 & 0 & 0 & 0 & 0 & 1 & 0 \\
\hline Staphylococcus aureus (8) & 7 & 0 & 1 & 1 & 2 & 2 & 0 & 1 & 1 & 3 & 1 \\
\hline Staphylococcus carnosus (5) & 5 & 1 & 5 & 2 & 4 & 5 & 3 & 4 & 4 & 5 & 5 \\
\hline Staphylococcus caseolyticus (2) & 0 & 0 & 0 & 0 & 0 & 0 & 0 & 1 & 2 & 0 & 0 \\
\hline Staphylococcus delphini (1) & 1 & 0 & 0 & 0 & 0 & 0 & 0 & 1 & 1 & 0 & 0 \\
\hline Staphylococcus epidermidis (2) & 1 & 0 & 0 & 0 & 0 & 0 & 0 & 0 & 0 & 0 & 0 \\
\hline Staphylococcus gallinarum (1) & 1 & 1 & 0 & 0 & 1 & 0 & 0 & 0 & 0 & 0 & 0 \\
\hline Staphylococcus intermedius (2) & 2 & 1 & 0 & 1 & 1 & 0 & 0 & 0 & 0 & 0 & 1 \\
\hline Staphylococcus lentus (1) & 0 & 0 & 0 & 0 & 1 & 0 & 0 & 0 & 0 & 0 & 0 \\
\hline Staphylococcus sciuri (1) & 1 & 0 & 0 & 0 & 1 & 0 & 0 & 0 & 0 & 0 & 0 \\
\hline Streptococcus equi ssp. zooepidemicus (8) & 7 & 3 & 2 & 2 & 6 & 4 & 2 & 5 & 3 & 1 & 4 \\
\hline Streptococcus macacae (1) & 0 & 0 & 0 & 0 & 0 & 0 & 0 & 0 & 0 & 0 & 0 \\
\hline Streptococcus porcinus (1) & 0 & 0 & 0 & 0 & 0 & 0 & 0 & 0 & 0 & 0 & 0 \\
\hline Streptococcus suis (1) & 1 & 1 & 0 & 0 & 0 & 1 & 0 & 1 & 0 & 0 & 1 \\
\hline Vibrio cholerae Non 01 (1) & 1 & 0 & 0 & 0 & 0 & 0 & 0 & 0 & 0 & 0 & 0 \\
\hline Total (217) & 194 & 73 & 22 & 59 & 95 & 56 & 35 & 57 & 51 & 129 & 92 \\
\hline${ }^{*}$ Percent resistant bacteria (211) & 89.6 & 31.8 & 7.6 & 25.1 & 42.2 & 23.7 & 13.7 & 24.2 & 21.3 & 58.8 & 37.9 \\
\hline Resistant GPBs (52) & 40 & 45 & 44 & 43 & 30 & 40 & 46 & 39 & 39 & 40 & 14 \\
\hline Resistant GNBs (159) & 149 & 99 & 151 & 115 & 92 & 121 & 136 & 121 & 127 & 47 & 72 \\
\hline
\end{tabular}

${ }^{*}$ Calculated only for bacterial strains ( $\left.n=211\right)$; GPBs, Gram positive bacteria; GNBs, Gram negative bacteria; number in parentheses indicate the number of strains tested; A, ampicillin $(10 \mu \mathrm{g})$; AZ, azithromycin ( $15 \mu \mathrm{g})$; CEO, citronella essential oil $(2 \mu \mathrm{L})$; Ct, Cefotaxime $(30 \mu \mathrm{g})$; C, chloramphenicol $(30 \mu \mathrm{g})$; Cf, ciprofloxacin $(5 \mu \mathrm{g})$; Co, cotrimoxazole (sulfamethoxazole $23.75 \mu \mathrm{g}$ + trimethoprim $1.25 \mu \mathrm{g})$ ); G, gentamicin $(10 \mu \mathrm{g}$ ); MD, multiple drug resistance (resistant to 3 or more antimicrobials); Nf, nitrofurantoin $(300 \mu \mathrm{g}) ; \mathrm{T}$, tetracycline $(30 \mu \mathrm{g})$.

Table 1: Antimicrobial drug and citronella essential oil (2 $\mu \mathrm{L}$ disc) resistance in strains of veterinary clinical significance and isolated from different sources.

\section{Source (nos. Types of Bacteria tested (number of isolates)} of strains)

Air (3)

Buffalo (6) Pseudomonas aeruginosa 1, Actinobaccilus seminis 1, Staph. gallinarum 1

Alkaligenes faecalis 1, Alk. Denitrificans 1, Erwinia cyperipedii 1, Klebsiella pneumoniae 2, Pse. testosteronii 1

Cattle(53) Aerococcus spp. 2, Aeromonas eucranophila 1, Bacillus spp. 1, Brucella abortus 10, 4 Enterobacter agglomerans 2, Ent. Amnigenus 1, Enterococcus spp. 2, Erwinia ananas 1, Escherichia coli 15, K. pneumoniae 6, Morganella morganii 1, Pasteurella langaensis 1, Pediococcus spp. 1, Pragia fontium 2, Proteus mirabilis 1, Proteus penneri 1, Pse. Aeruginosa 1, Staph. aureus 2, Streptococcus equi ssp. zooepidemicus 2

Dog (16) E. coli 1, P. mirabilis, 3, P. penneri 1, Pse. Aeruginosa 1, Raoultella terrigena 1, 13 Sphingomonas echinoides 2, Staph. Caseolyticus 2, Staph. Delphini 1, Staph. Intermedius 2, Staph. Lentus 1, Staph. sciuri 1

Elephant (7) Bacillus ssp. 1, E. coli 1, Ent. Agglomerans 1, Enterococcus spp. 1, Micrococcus spp. 7 1, Staph. Aureus 1, Strept. equi ssp. zooepidemicus 1

\section{Number of strains resistant to}

\begin{tabular}{l|l|l|l|l|l|l|l|l|l|l|} 
CEO & T & G & Nf & Co & Cf & C & Az & Ct & A & MD
\end{tabular}

\begin{tabular}{l|l|l|l|l|l|l|l|l|l|l|}
2 & 1 & 0 & 1 & 3 & 0 & 0 & 0 & 1 & 1 & 1
\end{tabular}

\begin{tabular}{ll|l|l|l|l|l|l|l|l|l}
6 & 4 & 0 & 3 & 3 & 4 & 2 & 2 & 0 & 6 & 4
\end{tabular}

\begin{tabular}{|l|l|l|l|l|l|l|l|l|l|}
19 & 2 & 13 & 24 & 14 & 2 & 17 & 9 & 38 & 24 \\
\hline
\end{tabular}

.
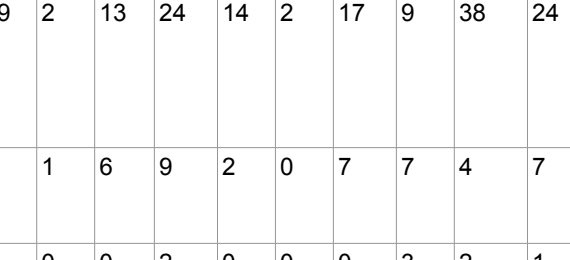


\begin{tabular}{|c|c|c|c|c|c|c|c|c|c|c|c|c|}
\hline Horse (9) & Bacillus licheniformis 1, E. coli 3, R. terrigena 1, Strept. zooepidemicus 4 & 9 & 6 & 3 & 3 & 9 & 5 & 2 & 4 & 4 & 3 & 6 \\
\hline Human (20) & $\begin{array}{l}\text { Acinetobacter Iwoffii 1, Actinobacillis spp. 1, Bacillus spp. 1, E. coli 1, Moraxella } \\
\text { osloensis 2, Pasteurella pneumotropica 2, Pse. Aeruginosa 1, Edwardsiella hoshniae } \\
\text { 1, R. terrigena 2, Staph. Aureus 1, Staph. Carnosus 5, Staph. Epidermidis 1, Strept. } \\
\text { zooepidemicus } 1\end{array}$ & 17 & 3 & 9 & 5 & 10 & 9 & 7 & 9 & 8 & 13 & 10 \\
\hline Mithun (18) & $\begin{array}{l}\text { Citrobacter freundii 1, Ent. Agglomerans } 3 \text {, Enterococcus spp. 3, Erwinia ananas 1, E. } \\
\text { coli 5, Hafnia alvei 1, K. pneumoniae 2, Pse. Aeruginosa 1, Staph. aureus } 2\end{array}$ & 17 & 3 & 1 & 5 & 5 & 3 & 2 & 2 & 4 & 11 & 6 \\
\hline Peafowl (5) & E. coli 1, Ent. Agglomerans 2, Staph. aureus 2, & 5 & 1 & 0 & 1 & 4 & 1 & 0 & 0 & 2 & 1 & 1 \\
\hline Pig (29) & $\begin{array}{l}\text { Achromobacter xyloxidans } 1 \text {, Aeromonas media } 1 \text {, Aeromonas salmonicida ssp. } \\
\text { salmonicida } 1 \text {, Edwardsiella. Tarda } 2 \text {, E. coli 12, K. pneumoniae } 1 \text {, Micrococcus spp. } 1 \text {, } \\
\text { P. multocida type D 1, Pse. Aeruginosa 2, Pse. Vesicularis } 1 \text {, Salmonella Adelaide 2, } \\
\text { Salmonella Kentucky 2, Strept. porcinus } 1 \text {, Vibrio cholerae Non } 011\end{array}$ & 25 & 17 & 0 & 4 & 6 & 8 & 8 & 0 & 1 & 18 & 12 \\
\hline Rabbit(4) & Aeromonas caviae 1, Bacillus spp. 2, Pse. aeruginosa 1 & 4 & 0 & 0 & 1 & 1 & 0 & 1 & 1 & 1 & 3 & 1 \\
\hline Rhino (6) & $\begin{array}{l}\text { E. coli 1, K. pneumioniae 1, Pse. Pseudoalcaligenes 1, Strept. Macacae 1, Strept. Suis } \\
\text { 1, Staph. aureus } 1\end{array}$ & 4 & 2 & 0 & 1 & 1 & 2 & 0 & 4 & 0 & 2 & 2 \\
\hline $\begin{array}{l}\text { Swamp Buffalo } \\
(29)\end{array}$ & $\begin{array}{l}\text { Aeromonas media 2, Alkaligenes faecalis 1, Citrobacter amalonaticus 1, Ent. } \\
\text { Agglomerans 12, E. coli } 5, K \text {. pneumoniae } 4 \text {, Kluyvera ascorbata 1, Kluy. Crocrescens } \\
\text { 1, Pes. Pseudoalkaligenes } 1 \text {, Pse. testosteronii } 1\end{array}$ & 28 & 4 & 0 & 10 & 10 & 1 & 5 & 3 & 5 & 20 & 9 \\
\hline Reference (6) & $\begin{array}{l}\text { Brucella abortus } 2 \text { (Strain } 19 \text { and Strain 99), Listeria Monocytogenes } 1 \text { (MTCC839), } \\
\text { Pasteurella multocida type B } 2 \text { (P52, Soron), Staph. epidermidis } 1 \text { (MTCC449) }\end{array}$ & 4 & 0 & 0 & 0 & 2 & 1 & 0 & 2 & 0 & 2 & 2 \\
\hline Total & & 189 & 67 & 16 & 53 & 89 & 50 & 29 & 51 & 45 & 124 & 86 \\
\hline
\end{tabular}

Number in parentheses indicate the number of strains tested; A, ampicillin (10 $\mu \mathrm{g})$; $\mathrm{AZ}$, azithromycin $(15 \mu \mathrm{g})$; CO, citronella essential oil $(2 \mu \mathrm{L})$; Ct, cefotaxime $(30 \mu \mathrm{g})$; $\mathrm{C}$, chloramphenicol $(30 \mu \mathrm{g})$; Cf, ciprofloxacin $(5 \mu \mathrm{g})$; Co, cotrimoxazole (sulfamethoxazole $23.75 \mu \mathrm{g}+$ trimethoprim $1.25 \mu \mathrm{g})$ ); $\mathrm{G}, \mathrm{gentamicin}(10 \mu \mathrm{g})$; MD, multiple drug resistance (resistant to 3 or more antimicrobials); Nf, nitrofurantoin $(300 \mu \mathrm{g}) ; \mathrm{T}$, tetracycline $(30 \mu \mathrm{g})$.

MTCC strains were procured from MTCC, Chandigarh, India, Brucella strains were procured from National Brucella Centre, and Pasteurella strains from CADRAD, Indian Veterinary Research Institute, Izatnagar, India.

Table 2: Source wise distribution of different bacteria (211) tested for sensitivity to antimicrobial drugs and citronella essential oil.

Citronella oil (CAS: 8000-29-1, Pcode 101178470) having geraniol as main constituent was purchased from Sigma Aldrich Chemie $\mathrm{GmbH}$, Germany.

\section{Antibiotic sensitivity assay}

Sensitivity of all 217 strains including Candida and Aspergillus strains to antibiotics (ampicillin, $10 \mu \mathrm{g}$; azithromycin, $15 \mu \mathrm{g}$; cefotaxime, $30 \mu \mathrm{g}$; chloramphenicol, $30 \mu \mathrm{g}$; ciprofloxacin, $5 \mu \mathrm{g}$; cotrimoxazole, sulfamethoxazole $23.75 \mu \mathrm{g}$ +trimethoprim $1.25 \mu \mathrm{g}$; gentamicin, $10 \mu \mathrm{g}$; nitrofurantoin, $300 \mu \mathrm{g}$ and tetracycline, $30 \mu \mathrm{g}$ ) was determined with standard disc diffusion assay as per CLSI [16] guidelines on $\mathrm{MH}$ agar. Antibiotic sensitivity assay was performed in duplicate on Mueller Hinton (MH) agar (BD BBL and Difco). For Moraxella, Streptococcus, Brucella and Pasteurella strains instead of $\mathrm{MH}$ agar brain heart infusion (BHI) agar (BD BBL and Difco) was used [15]. All strains were tested at $37^{\circ} \mathrm{C}$ under aerobic growth conditions but Brucella strains were tested under micro aerobic environment in $5 \% \mathrm{CO}_{2}$ enriched environment in McInntosh jar. Results were interpreted as per CLSI [16] guidelines and strains were designated as sensitive or resistant depending on zone of inhibition. Strains resistant to three or more antimicrobials were classified as multiple drug resistant (MDR).

\section{Statistical analysis}

To determine correlation between diameter of zone of inhibition (in $\mathrm{mm}$ ) of bacteria around antimicrobial and CEO discs correlation coefficient ( $r$ ) was calculated using Microsoft Exel-7. To estimate association between sensitivity of bacteria to antimicrobials, including CEO and source of their source of isolation, species and association with disease, $\chi^{2}$ test and odds ratio analysis was performed in MS Office Excel-2007. The statistical comparison was done for only those groups of bacteria or sources of bacteria where number (n) of strains tested was $\geq 10$.

\section{Results and Discussion}

Results of antimicrobial and CEO sensitivity assays of 217 microbial strains of 65 species belonging to 34 genera (Table 1) revealed that citronella oil could inhibit growth of only 23 (10.6\%) microbes. In the study none of Candida and Aspergillus strain was sensitive to any of the nine antimicrobials tested. Resistance of yeasts and molds to antibacterial drugs is constitutive and anticipated being inherited [1517]. Only Candida but none of the five Aspergillus strain was sensitive to CEO. Although CEO has been reported earlier to inhibit growth of several fungi including reference $A$. niger $[1,5,7,8,18]$ strains. However, it was not found inhibitory to any of the five potentially toxigenic Aspergillus strains in the present study. In earlier studies $[2,6,10]$, CEO could inhibit growth of $A$. niger in concentrations higher than $0.125 \%(\mathrm{v} / \mathrm{v})$ however in our experiment no inhibition was seen around discs containing $2 \mu \mathrm{L}$ of CEO. This variation might be attributed due to several reasons including difference in strains, methodology and CEO itself as observed earlier $[2,6,10]$ and also due to variation in composition of CEO [1].

Citronella oil could inhibit growth of only $22(10.4 \%)$ out of 211 bacteria while the least effective antibiotic (ampicillin) could inhibit growth of $41.2 \%$ bacterial strains. Similar pattern of resistance in bacterial strains of different animal and environmental origin has been reported for other essential oils including closely related lemongrass oil [19].

Gentamicin was the most effective antimicrobial inhibiting 92.4\% bacterial isolates followed by chloramphenicol (86.3\%), cefotaxime (78.7\%), ciprofloxacin (76.3\%), azithromycin (75.6\%), nitrofurantoin (74.9\%), tetracycline (68.2\%) and cotrimoxazole (57.8\%). The resistance pattern for different antibiotics varied among strains of different species (Table 1) and strains of different sources (Table 2). Similar variation in sensitivity of bacterial strains to various antimicrobials is of common occurrence all over the world [16] and similar patterns have been reported earlier for bacterial isolates from veterinary clinical cases in India too [20].

Sensitivity to CEO was more common among GPBs with 4.5 times higher odds of being sensitive than GNBs (p, 0.0006) similar to their 
Citation: Singh BR, Agrawal R, Prasanna Vadhana, Bhardwaj M, Dubey S (2015) Antimicrobial Activity of Citronella Essential Oil on Antimicrobial Drug Resistant Bacteria from Veterinary Clinical Cases. Clin Med Biochem Open Access 1: 106. doi:10.4172/2471-2663.1000106

Page 5 of 9

higher sensitivity to gentamicin (p, 0.01) than GNBs. Similar pattern of higher resistance in GNBs has also been reported with lemongrass oil, a close relative of citronella oil [19].

Probability of GPBs being resistant for tetracycline ( $\mathrm{p}, 0.001)$ and ampicillin (,$<0.0001)$ was significantly higher than GNBs and similar pattern has been observed for these antibiotics earlier worldwide $[16,17,20]$. GNBs were significantly more MDR type than GPBs ( $p$, 0.02). MDR for 3-5 drugs was significantly more common in GNBs ( $\mathrm{p}$, 0.001 ) but there was no much difference in MDR for six or more drugs between GPBs and GNBs ( $p, 0.36$ ). Higher proportion of MDR strains among GNBs is common all over the globe and has been commonly reported in India and abroad [17,20-22].

Significantly ( $p, 0.006$ ) less number of MDR strains was sensitive to CEO, than non-MDR strains (Table 3; Figure 1). Similarly, probability of ampicillin resistance was more in CEO resistant strains. However, no significant association could be established between resistance to CEO and other antimicrobials used in the study. Only few studies have earlier compared the sensitivity of MDR and non-MDR strains to herbal oils or herbal antimicrobials, however, on meta-analysis of published data [23] it was evident that bacteria having MDR were more commonly resistant to essential oil of lemongrass and sandal wood. In the same study [23] no correlation could be found between ampicillin resistance and resistance to essential oil of sandal wood, lemongrass, Artemesia vulgaris, and patchouli. However, sensitivity to alcoholic extract of Zanthxylum rhetsa and Ageratum conyzoides was significantly (p, 0.02)

\begin{tabular}{|c|c|c|}
\hline MDR & G+ve bacteria (source of isolation) & G-ve bacteria (source of isolation) \\
\hline 9 & S. carnosus1 (doctors' hand) & Actinobacillus spp. 1(UTI), Ps. aeruginosa 1 (UTI) \\
\hline \multirow[t]{3}{*}{7} & S. carnosus 2 (doctors' hand) & E. coli 3 (cattle aborted fetus 2 , dog wound 1 ) \\
\hline & \multirow[t]{2}{*}{ St. equissp. zooepidemicus2 (horse nose) } & R. terrigena 1 (horse nose) \\
\hline & & Proteus mirabilis 1 (dog otorrhea) \\
\hline \multirow[t]{3}{*}{6} & S. carnosus 1 (doctors' hand) & Erwinia cyperipedii 1 (buffalo aborted fetus) \\
\hline & S. aureus 1 (infertile mithun) & E. coli 2 (cattle aborted fetus) \\
\hline & St. equi ssp. zooepidemicus 1 (horse nose) & B. abortus 2 , cattle aborted fetus \\
\hline \multirow[t]{6}{*}{5} & & E. coli 6 (cattle aborted fetus 1 , dead rhino 1 , dead peafowl 1 , dead pig 3 ) \\
\hline & & Brucella abortus 1 (cattle aborted fetus) \\
\hline & & Ent. agglomerans 2 ( vagina of infertile mithun and swamp buffalo) \\
\hline & & K. pneumoniae 2 (vagina of infertile mithun 1, buffalo aborted fetus 1 ) \\
\hline & & Ps. pseudoalcaligenes 1 (vagina of infertile mithun) \\
\hline & & R. terrigena 1 (dog otorrhoea) \\
\hline \multirow[t]{9}{*}{4} & \multirow[t]{9}{*}{ S. carnosus1 (doctors'hand) } & Aeromonas media 1 (dead pig) \\
\hline & & B. abortus 4 (cattle aborted fetus 3 , reference 1 ) \\
\hline & & Ent. agglomerans 4 (vagina of infertile mithun) \\
\hline & & E. coli 6 (dead pigs 3 , human UTI 1 , horse nose 1 , cattle aborted fetus 1 ) \\
\hline & & K. pneumoniae 1 (vagina of infertile mithun) \\
\hline & & Morganella morganii 1 (cattle mastitis) \\
\hline & & Proteus penneri 1 (dog otorrhoea) \\
\hline & & Proteus mirabilis 2 (dog otorrhoea) \\
\hline & & Ps. aeruginosa 1 (dairy farm air) \\
\hline
\end{tabular}

associated positively with sensitivity to ampicillin [23].

Though bacterial strains of 62 species belonging to 32 genera were included in the study, number of strains belonging to different species were $<10$ except of Brucella abortus (12), Enterobacter agglomerans (20), E. coli (45), Klebsiella pneumoniae (16), Pseudomonas spp. (13), Staphylococcus spp. (23) and Streptococcus spp. (11). Statistical analysis for association of drug resistance with different bacteria was calculated for those bacteria with $>10$ strains included in the study.

On comparing sensitivity of strains belonging to different groups in strains of E. coli (p, 0.02), Klebsiella (p, 0.03), Brucella (p, 0.05) and Enterobacter ( $\mathrm{p}, 0.08)$ was much more than in strains of Streptococcus (72.7\%). More strains of klebsiellae (p, 0.05) and brucellae (p, 0.08) were resistant to CEO than of staphylococci $(78.3 \%)$ but there was no difference for CEO resistance among other types of bacteria. The similar variation in sensitivity of different bacteria to CEO has also been observed earlier [2].

All strains of klebsiellae, raoultellae, staph. Carnosus, salmonellae, and aeromonads (except a strain of Aeromonas salmonicida ssp. salmonicida) were resistant to ampicillin. Besides majority of brucellae (11/12), E. agglomerans (16/20), P. aeruginosa (10/13) and E. coli $(31 / 45)$ were resistant to ampicillin. Ampicillin resistance in klebsiellae, raoultellae and aeromonads is common and often inherited, and ampicillin sensitive strains are rarely been reported [24,25]. Due to of pathogens (Table 1) it was evident that probability of CEO resistance 


\begin{tabular}{|l|l|}
\hline St. suis 1 (dead rhino) & Alkaligenes faecalis 1 (buffalo aborted fetus) \\
\hline St.equi ssp. zooepidemicus 1 (calf diarrhoea) & B. abortus 3 (cattle aborted fetus2, reference 1) \\
\hline Enterococcus spp. 1 (cattle aborted fetus) & Edwardsiella hoshniae 1 (human UTI) \\
\hline S. intermedius 1 (dog wound) & Edwardsiella tarda 1 (pig diarrhoea) \\
\hline Micrococcus spp. 1 ( tooth canal of elephant) & Ent. agglomerans 2 (vagina of infertile mithun and healthy swamp buffalo) \\
\hline & E. coli 6 (horse nose 1, cattle aborted fetus5) \\
\hline Hafnia alvei 1, infertile mithun vagina \\
\hline K. pneumoniae 3 (cattle mastitis 1, vagina of healthy swamp buffalo 1, pig nose 1) \\
\hline Ps.aeruginosa 1 (vagina ofinfertile mithun) \\
\hline Salmonella Kentucky 2 (spleen of dead pig)
\end{tabular}

B., Brucella; E., Escherichia; Ent., Enterobacter; K., Klebsiella; Ps., Pseudomonas; R., Raoultella; S. Staphylococcus; St., Streptococcus.; MDR, multiple drug resistance to number of antimicrobials ( $\geq 3$ ). None of the MDR strains, except two E. coli from dead pigs (resistant to 5 drugs) and one Strept. equi ssp. zooepidemicus (resistant to three drugs) from diarrhoeic calf was sensitive to citronella essential oil.

Table 3: Multiple drug resistant (MDR) strains of Gram+ve and Gram-ve bacteria isolated from different sources.

frequent resistance to it, this antibiotic has never been considered an option for treatment of brucellosis and Pseudomonas infections [21,26].

With respect to tetracycline resistance, E. coli (p, <0.01) strains had more probability of being resistant $(60 \%)$ to it than brucellae (16.7\%), and enterobacteria (15\%). Both E. coli (p, 0.0002) and Klebsiella (p, 0.08) strains were more often resistant to tetracycline than staphylococci (13\%). Pseudomonads were more often resistant (46.2\%) to tetracycline than Enterobacter (p, 0.05) and Staphylococcus ssp. (p, 0.03) strains. Though tetracycline is a comparatively older antibiotic and resistance to it is common in most of the bacteria [19], it (as doxicycline) is still considered drug of choice for treatment of brucellosis [26] due to sensitivity of brucellae to tetracyclines. In this study too brucellae were more often sensitive to tetracycline despite of having MDR.

For gentamicin, sensitivity of strains of different bacteria (73.9\%$100 \%)$ didn't differ much, except for the strains of staphylococci and streptococci, which were more often resistant to gentamicin than strains of enterobacteria (p, 0.01, 0.05) and klebsiellae (p, 0.03, 0.08). Besides, Staphylococcus strains were also more commonly resistant to gentamicin (26.1\%) than E. coli (p, 0.03) and B. abortus (p, 0.05). Aminoglycoside resistance in most of the GPBs including staphylococci and streptococci is reported more commonly than in GNBs[27-30]. Due to wide spectrum of activity and its effectiveness to inhibit majority of bacterial strain it is still considered to be the drug of last resort in many life threatening infections [27].

More number of E. agglomerans (50\%) and Pseudomonas (53.8\%) strains were nitrofurantoin resistant than strains of Staphylococcus ( $\mathrm{p}, 0.03,0.02)$ and Streptococcus ( $\mathrm{p}, 0.08,0.07)$ species. However, E. coli strains were less often resistant to nitrofurantoin $(8.9 \%)$ than Pseudomonas (p, 0.0003) and K. pneumoniae (p, 0.008) strains. Similar pattern has been observed earlier for bacteria of veterinary clinical origin $[15,20]$.

All B. abortus strains were resistant to co-trimoxazole and differed significantly from other bacteria $(\mathrm{p}, 0.02)$ and observations are in concurrence to earlier reports [26]. Probability of co-trimoxazole resistance was more among Pseudomonas (61.5\%) strains than in $K$. pneumoniae (25\%; p, 0.05) strains. In general, streptococci (45.5\%; p, $0.02)$ and staphylococci (30.4\%; $p, 0.07)$ were more often resistant to ciprofloxacin than K. pneumoniae (6.3\%), Pseudomonas (7.7\%; p, 0.03), and E. agglomerans (10\%; p, 0.02) strains. Similar to cocci, more E. coli
(42.2\%) strains were ciprofloxacin resistant than K. pneumoniae (p, 0.0009), Pseudomonas (p, 0.02) and E. agglomerans strains (p, 0.01). However, B. abortus were even more (58.3\%) commonly resistant to ciprofloxacin than E. agglomerans (p, 0.003), K. pneumoniae (p, 0.003 ) and Pseudomonas (p, 0.007) strains. An observation of more ciprofloxacin resistance in cocci than among GNBs is in concurrence to earlier reports $[16,17]$.

Resistance to chloramphenicol was not detected in brucellae but was common among pseudomonads (38.5\%). However, sensitivity to chloramphenicol not varied significant $(\mathrm{p}>0.05)$ among strains of other bacteria (6.3-25\%). Among pseudomonads chloramphenicol resistance was significantly more common than in strains of $B$. abortus (p, 0.02), E. coli (p, 0.07), K. pneumoniae (p, 0.03) and staphylococci (p, 0.08). Sensitivity of Brucella to chloramphenicol is a well-documented [26]. In recent years emergence of chloramphenicol resistance in pseudomonads has become a serious problem both in strains of human and animal origin $[15,16]$.

More than $83 \%$ of the $B$. abortus strains were resistant to azithromycin while all the E. agglomerans strains were sensitive, all other bacteria stood in between the two extremes. Brucella abortus were more resistant to azithromycin than E. agglomerans (p, <0.0001), E. coli (p, <0.0001), Pseudomonas (p, 0.008) and Staphylococcus ( $0.003)$ strains. More number of streptococci $(54.5 \%)$ was resistant to azithromycin than E. coli (p, 0.01) but difference was insignificant with respect to strains of all other bacteria except all sensitive strains of $E$. agglomerans. Although azithromycin is broad spectrum antibiotic, it is recommended commonly for infection with GPBs [15,16]. Emergence of azithromycin resistance in GPBs from veterinary clinical cases is of importance having knowledge that this drug is rarely used in animals in India [28]. This might be due to horizontal transfer of either resistance genes (R-factors) or the bacteria itself from human to animals.

Sensitivity to cefotaxime among strains of different bacteria (8.3-30.8\%) had no significant variation. However for ampicillin, streptococci $(90.9 \%)$ and staphylococci $(65.2 \%)$ were more sensitive than GNBs $(<25 \%)$. Probability of being sensitive to cefotaxime was even more among streptococci than staphylococci (p, 0.05). More sensitivity to cefotaxime in GPBs than GNBs has also been reported earlier in bacteria of animal origin [20,29].

Most of the B. abortus strains (83.3\%) were MDR type and MDR was much more common in brucellae than in other bacteria including 
K. pneumoniae (p, 0.02), E. agglomerans (p, 0.03), Pseudomonas (p, 0.02), Staphylococcus (, 0.02 ) and Streptococcus ( $\mathrm{p}, 0.01)$ strains. Next to B. abortus, MDR was common in E. coli (51.1\%) and it was significantly more common than in E. agglomerans (p, 0.03), K. pneumoniae (p, 0.03) and Staphylococcus (p, 0.004) strains. MDR in Brucella strains is rarely reported (Corbel, 2006) and its detection is of public health concern due to zoonotic nature of the pathogen. MDR strains of E. coli have haunted globally and are one of the common global problems $[15,16,22]$.

Analysis of data for source of bacterial strains and antimicrobial drug resistance (Table 2) indicated that CEO resistance (96.6\%) was relatively more common ( $\mathrm{p}, 0.08)$ among strains isolated from swamp buffaloes (Figure 2) than in strains from dogs (81.3\%). However, strains from other sources had no significant difference for sensitivity to CEO. The dogs and swamp buffaloes are two extremes in our range of sources of bacteria studied, one the closest to human and other roaming in semi-wild stage in Nagaland eating different types of herbs including citronella grass common in Nagaland $[29,30]$. The continuous exposure of microbes of swamp buffaloes to citronella might be responsible for harbouring CEO resistant strains by swamp buffaloes, though it needs further confirmation either it is their feeding habit or any other determinant involved.

Tetracycline resistance (TR) was most common in bacteria isolated from pigs (58.6\%) and dogs (43.8\%). TR was significantly less common in strains of human origin (15\%) than strains of cattle (p, 0.08), dog $(p, 0.06)$ and pig ( $p, 0.002)$ origin. More of the swamp buffalo origin bacteria were tetracycline sensitive $(13.8 \%)$ than strains from cattle (p, 0.03), dogs ( $p, 0.03)$ and pigs (0.0004). Similarly more isolates of mithun origin $(16.7 \%)$ were sensitive to tetracycline than isolates of $\operatorname{dog}(p, 0.08)$ and pig $(p, 0.005)$ origin. Similar pattern for tetracycline sensitivity among bacteria of mithun and swamp buffalo origin has been observed in earlier studies too $[29,31]$. Higher resistance to tetracycline in bacteria of pig and dog origin might be due to consumption of more concentrate feed and also due to their similar food habits as of human and sharing of similar kind of microbe $[15,17,20]$.

In contrast to tetracycline resistance, gentamicin resistance was significantly more common ( $\mathrm{p},<0.01)$ among bacteria of human origin (45\%) than isolates from animals. Few strains of dog $(6.3 \%)$, mithun (5.6\%) and cattle (3.8\%), had resistance to gentamicin but none of the isolates of swamp buffalo and pig origin been resistant to gentamicin. The restricted use of gentamicin in animals in India [28] might be considered responsible for low prevalence of gentamicin resistant bacteria in animals.

Most bacterial strains of pig origin (86.2\%) were sensitive to nitrofurantoin while more (p, 0.07) strains isolated from dogs $(62.5 \%)$ and swamp buffaloes (65.5\%) were resistant. Nitrofurantoin resistance among bacterial strains from other animals had no significant variation $(p,>0.2)$ in their sensitivity to nitrofurantoin. Nitrofurantoin is a rarely used drug in animals except limited use of similar drug furazolidone in wound dressing and in passaries in India [28] that is why despite of being an old antimicrobial resistance was comparatively uncommon.

Majority of strains of dog origin were resistant to cotrimoxazole (56.3\%) while about $80 \%$ of bacterial isolates from pig were sensitive. Cotrimoxazole sensitivity among isolates from pigs was significantly lower than those from dogs ( $p, 0.02)$ and humans ( $p, 0.03)$ while there was not much difference among strains of other animals $(\mathrm{p}$, $>0.09$ ). Cotrimoxazole though commonly used in animals [28] is not a preferred drug for pigs [15]. Less use of co-trimoxazole in pigs might be associated with occurrence of co-trimoxazole sensitive strains in pigs.
Sensitivity to ciprofloxacin was common in bacteria from swamp buffaloes (96.6\%), mithuns (83.3\%) and dogs (87.5\%) while only $73.6 \%$ of cattle and $72.4 \%$ of pig origin strains were sensitive. However, only $55 \%$ strains of human origin were sensitive to ciprofloxacin which was significantly higher than for strains of $\operatorname{dog}(p, 0.04)$, mithun ( $p, 0.06)$ and swamp buffalo ( $p, 0.004)$ origin. Among animal origin strains, less isolates of swamp buffalo origin were resistant to ciprofloxacin than isolates of pig (p, 0.01) and cattle (p. 0.01$)$ origin. Ciprofloxacin is one of the most widely used injectable antibiotics in human while its equivalent (enerfloxacin) in animals in India [15]. However, enerofloxacin has rarely been used in swamp buffaloes and mithuns because of their semi-wild nature and difficulty in use of injectable antibiotics [29,31]. Hence, occurrence of ciprofloxacin resistant strains in mithun and swamp buffaloes might be rarer than in other animals and humans.

None of bacterial isolates from dogs and only few from cattle (3.8\%) and mithun (11.1\%) had resistance to chloramphenicol while more (p, <0.1) strains of human (35\%) and pig (27.6\%) origin were resistant to chloramphenicol. Rare occurrence of chloramphenicol resistance among strains of animal origin might be due to less use of chloramphenicol for animals in India [15]. On the other hand, azithromycin resistance was rare in isolates of pig origin $(0 \%)$ and common in strains of $\operatorname{dog}(43.8 \%)$ and human (45\%) origin. The sensitivity to azithromycin was more common among strains of swamp buffalo (p, 0.03), mithun ( $p, 0.08)$ and pigs (p, 0.0006) than strains of cattle (p, <0.08), human (p, <0.03) and dogs (,$<0.03)$. Azithromycin is not used in animals [15] but is a commonly used antibiotic in humans and is available without prescription in India [32]. Occurrence of azithromycin resistance in bacterial strains of dog and human origin might be due to close cohabitation of both and sharing (exchange) of zoonotic bacteria among the two species [33].

Bacterial isolates of $\operatorname{dog}(43.8 \%)$ and human $(40 \%)$ origin were more commonly resistant $(\mathrm{p}, \leq 0.04)$ to cefotaxime than isolates from pig (3.4\%), cattle (17\%), swamp buffalo (17.2\%) and mithun (22.2\%). Sensitivity ratio among bacteria from pig was significantly higher $(p, \leq$ 0.07 ) than isolates of any other animal. Higher resistance to cefotaxime in dog and human origin isolates might be due to sharing/ exchange of bacteria with each other and more frequent use of cefotaxime both in human and dogs than in other animals in India $[15,20]$.

Significantly more $(\mathrm{p}, \leq 0.03)$ bacterial isolates from dogs $(75 \%)$ were sensitive to ampicillin in comparison to other animals (Figure 2). Though very commonly used antibiotic in India, is rarely used in dog [15]; less use of the drug in dogs might be associated with frequent sensitivity of bacterial isolates of dog origin to ampicillin.

There was no significant difference $(\mathrm{p},>0.18)$ with respect to MDR in bacterial isolates of different animal and human sources (Table 3 ). The observation is quite in contradiction to earlier observation on more frequent MDR in bacterial strains in human beings in India [34] It might be due to fast spread of antimicrobial drug resistance and fast emergence and spread of MDR strains of bacteria both in animal and humans $[17,27]$.

Analysis of drug resistance among bacterial isolates associated with different disease conditions (Figure 3 ) indicated that in general more of the bacterial strains isolated from diarrhoeic cases were sensitive to antimicrobials than those isolated in association of other disorders in animals and humans. It might be due to the fact that diarrhoea is often a multi-etiologic disorder and associated with disturbed microflora rather than specific pathogen establishing itself through acquisition of specific virulence and antimicrobial drug resistance [35]. However, 


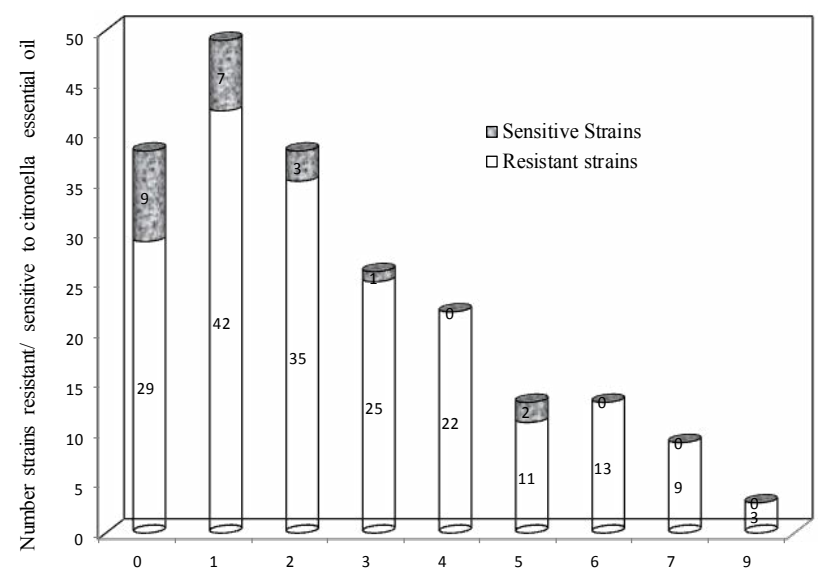

Resistant to number of antimicrobials

Figure 1: Multiple drug resistance and sensitivity to citronella essential oil in bacterial strains isolated from different animal sources.

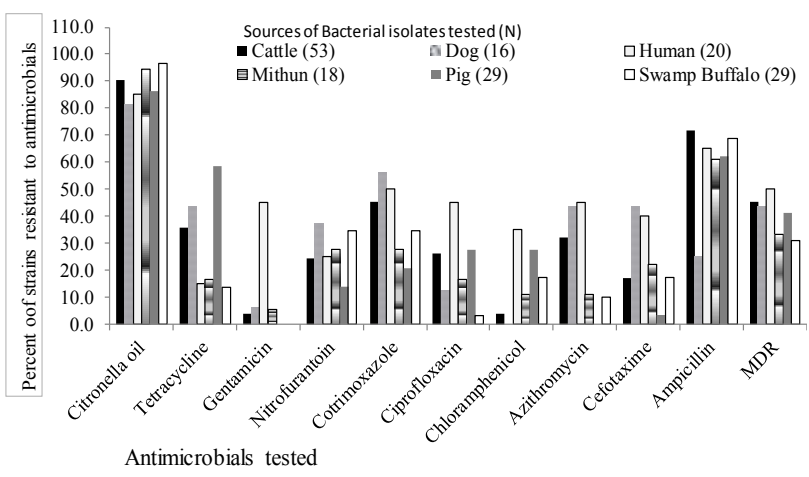

Figure 2: Antimicrobial drug resistance and multiple drug resistance (MDR) in bacterial strains from different sources.

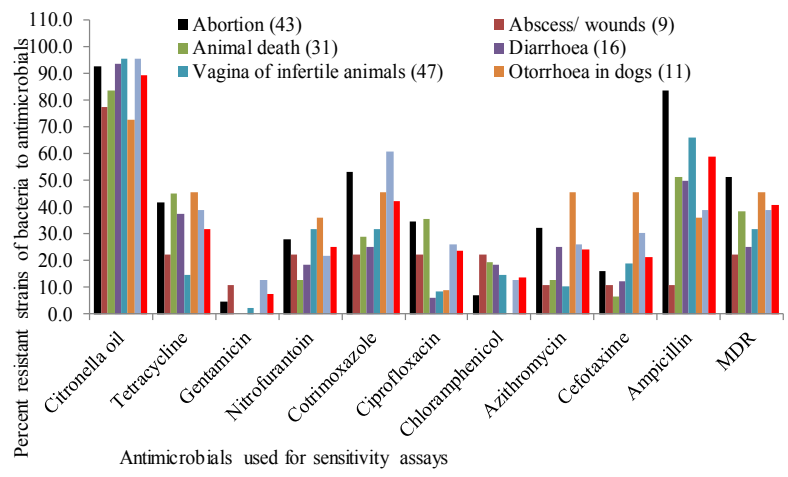

Figure 3: Antimicrobial drug resistance and multiple drug resistance (MDR) in bacterial strains associated with different disease conditions.

bacterial isolates from otorrhoea cases $(27.3 \%)$ were more commonly sensitive to CEO than those associated with abortion ( $\mathrm{p}, 0.06)$, infertility $(p, 0.01)$ and respiratory tract infection $(p, 0.05)$ cases. Majority of the bacteria isolated $(95.7 \%)$ from infertility cases and respiratory tract infections were resistant to CEO. In contrast, significantly more ( $\mathrm{p}$, $\leq 0.05)$ bacteria isolated from infertility cases $(85.1 \%)$ were sensitive to tetracycline than those associated with other ailments. It might be due to the fact that tetracycline is one of the rarely used drugs to treat uterine infections [36]. Gentamicin being one of the most effective antibiotics in the study could inhibit $>95 \%$ bacteria associated with different disease conditions in animals and human beings. However gentamicin could inhibit only $87 \%$ of bacterial strains associated with respiratory tract infections (RTI). Nitrofurantoin was the least effective antimicrobial on bacteria isolated from otorrhoea (63.6\%) and most effective on bacteria isolated from cases of septicaemia (87.1\%) leading to mortality. Cotrimoxazole inhibited $75 \%$ of bacteria from diarrhoeic cases while only $39.1 \%$ bacteria isolated from RTI cases (p, 0.03) and $46.5 \%$ from abortion cases (p, 0.03). Bacteria from abortion (53.5\%) and RTI $(60.9 \%)$ cases $(\mathrm{p}, \leq 0.05)$ were more commonly resistant to cotrimoxazole than those from diarrhoea (25\%), infertility $(31.9 \%)$ and mortality (29\%) cases. Indiscriminate use of cotrimoxazole as non-prescription drug in animals in India [15] might be responsible for frequent occurrence of cotrimoxazole resistance. Ciprofloxacin inhibited $>90 \%$ bacterial isolates from diarrhoea (93.7\%), infertility $(91.5 \%)$ and otorrhoea $(90.9 \%)$ cases while it was significantly $(p, \leq$ $0.05)$ less effective on bacteria associated with RTI $(73.9 \%)$, mortality (64.5\%) and abortion (65.1\%). It might be due to association of specific drug resistant pathogens with RTI and abortions, and also with frequent indiscriminate use of enerofloxacin in animals. Enerofloxacin has even been used as preservative in injectable vaccines intended for veterinary use in India $[37,38]$. None of bacterial isolates from otorrhoea and only $7 \%$ of isolates from abortions cases were resistant to chloramphenicol but $>80 \%$ bacterial isolates associated with other ailments too were sensitive to chloramphenicol. About $90 \%$ bacteria associated with infertility and mortality were sensitive to azithromycin which was significantly ( $\mathrm{p}, \leq 0.05)$ higher than those from cases of otorrhoea (54.5\%) and abortions (67.4\%). Cefotaxime was the most effective on bacteria isolated from blood of dead (93.5\%) and faeces of diarrhoeic (87.5\%) animals; however, it was significantly less effective $(\mathrm{p}, \leq 0.06)$ on bacteria causing otorrhoea (54.5\%). Bacteria from abortion cases $(83.7 \%)$ were more often resistant to ampicillin than isolates from blood of dead ( $p, 0.003)$, faeces of diarrhoeic ( $p, 0.008)$, and swabs from infertile (p, 0.05), otorrhoeic (p, 0.001) and RTI (p, 0.0002) cases. Bacteria isolated from otorrhoea (p, 0.07) and RTI (p, 0.03) were less resistant type even less than those from infertile animals.

The study indicated that some of the antimicrobials should be used with proper diagnosis and considering the system affected by the infection for effective antimicrobial therapy as indicated earlier $[15,16,23]$. With respect to MDR bacterial strains isolated from different disease conditions did not differ much $(\mathrm{p},>0.05)$ however, proportion was maximum among strains isolated from abortion (51.2\%) and minimum among strains associated with diarrhoea (25\%). It indicated that the pathogens associated with abortion needs to be considered serious threat for future planning for MDR control. High level of MDR in abortion associated pathogens might be of immense public health concern because such pathogens may contaminate the environment at large scale during abortion in large animals. Moreover, citronella essential oil may not be very promising antimicrobial in veterinary use due to frequent resistance in bacteria of animal origin to it.

\section{Acknowledgements}

Authors are thankful to Director and Joint Director $(R)$, Indian Veterinary Research Institute for permitting to study and for arranging funds. Authors are also thankful to Mr HC Joshi and Laikurahman for continuous laboratory assistance.

\section{References}

1. Nakahara K, Alzoreky NS, Tadashi Y, Yoshihashi T, Nguyen HTT, et al. (2013) Chemical composition and antifungal Activity of essential oil from Cymbopogon nardus (Citronella Grass). Japan Agric Res Quart 37: 249-252. 
2. Wei LS, Wee W (2013) Chemical composition and antimicrobial activity of Cymbopogon nardus citronella essential oil against systemic bacteria of aquatic animals. See comment in PubMed Commons below Iran J Microbiol 5: $147-152$.

3. Masetti A, Maini S (2006) Arm in cage tests to compare skin repellents against bites of Aedes albopictus. Bull Insectol 59: 157-160.

4. Arias BA, Ramón-Laca L (2005) Pharmacological properties of citrus and their ancient and medieval uses in the Mediterranean region. See comment in PubMed Commons below J Ethnopharmacol 97: 89-95.

5. de Billerbeck VG, Roques CG, Bessière JM, Fonvieille JL, Dargent R (2001) Effects of Cymbopogon nardus (L.) W. Watson essential oil on the growth and morphogenesis of Aspergillus niger. See comment in PubMed Commons below Can J Microbiol 47: 9-17.

6. Hammer KA, Carson CF, Riley TV (1999) Antimicrobial activity of essential oils and other plant extracts. See comment in PubMed Commons below J Appl Microbiol 86: 985-990.

7. Pattnaik S, Subramanyam VR, Kole C (1996) Antibacterial and antifungal activity of ten essential oils in vitro. See comment in PubMed Commons below Microbios 86: 237-246.

8. Pattnaik S, Subramanyam VR, Bapaji M, Kole CR (1997) Antibacterial and antifungal activity of aromatic constituents of essential oils. See comment in PubMed Commons below Microbios 89: 39-46.

9. Lertsatitthanakorn P, Taweechaisupapong S, Aromdee C, Khunkitti W (2006) In vitro bioactivities of essential oils used for acne control. Int J Aromather 16 43-49.

10. Luangnarumitchai S, Lamlertthon S, Tiyaboonchai W (2007) Antimicrobial activity of essential oils against five strains of Propionibacterium acnes. Mahido Uni. J Pharmac Sci 34: 60-64.

11. Prabuseenivasan S, Jayakumar M, Ignacimuthu S (2006) In vitro antibacterial activity of some plant essential oils. See comment in PubMed Commons below BMC Complement Altern Med 6: 39

12. Carter GR (1975) Diagnostic Procedures in Veterinary Microbiology (2nd edn), Charles $C$ Thomas Publishers, Springfield.

13. Singh BR (2009) Labtop for Microbiology Laboratory. Lambert Academic Publishing AG \& Co. KG, Dudweiler Landstr. Saarbrucken, Germany.

14. Singh BR (2013) Evaluation of antibacterial activity of Salvia officinalis [L.] sage oil on veterinary clinical isolates of bacteria. Noto-are: Med.

15. Singh BR (2013) Antimicrobial sensitivity assay and antimicrobial chemotherapy in Animals: A Practical approach. In: Singh BR, Somvanshi R, eds., Diseases of Animals: Diagnosis and Management, Indian Veterinary Research Institute, Izatnagar- 243 122, UP 1: 7-31.

16. CLSI (2014) Performance Standards for Antimicrobial Disk Susceptibility Tests. 24th Informational Supplement, Document M100-S24 and M11-A8, Clinical and Laboratory Standards Institute, Wayne, Pennsylvania.

17. Kumar S, Singh BR (2013) An Overview on Mechanisms and Emergence of Antimicrobials Drug Resistance. Ad Anim Vet Sci 1: 7-14.

18. Li WR, Shi QS, Ouyang YS, Chen YB, Duan SS (2013) Antifungal effects of citronella oil against Aspergillus niger ATCC 16404. See comment in PubMed Commons below Appl Microbiol Biotechnol 97: 7483-7492.

19. Singh BR, Singh V, Singh RK, Ebibeni N (2011) Antimicrobial activity of lemongrass (Cymbopogon citratus) oil against microbes of environmental, clinical and food origin. Int Res J Pharm Pharmacol 1: 228-236.

20. Singh BR, Verma R, Gupta CP (2012) Antimicrobial Drug Resistance in Bacteria Isolated from Sick Animals and Their Environment in Year 2011-2012 at Central Disease Diagnostic Laboratory, Indian Veterinary Research Institute, Izatnagar. Noto-are Med. (11152889): 1-3

21. Anonymous (2013) Antibiotic Resistance. A global survey. Salient surveys reports, Tamarisk House, High Street, Colne, Cambridgeshire PE28 3ND United Kingdom, 2013

22. Singh BR (2009) Thermotolerance and multidrug resistance in bacteria isolated from equids and their environment. See comment in PubMed Commons below Vet Rec 164: 746-750

23. Singh BR, Singh V, Ebibeni N, Singh RK (2013) Antimicrobial and Herbal Drug Resistance in Enteric Bacteria Isolated from Faecal Droppings of Common House Lizard/Gecko (Hemidactylus frenatus). See comment in PubMed Commons below Int J Microbiol 2013: 340848 .
24. Singh BR, Kulshreshtha SB (1993) Isolation of Ampicillin sensitive Aeromonas from aquatic foods with XLD Agar and ampicillin dextrin agar. J Food Sci Technol 30: 359-361.

25. Singh BR, Sharma V D (1999) Klebsiella, an emerging pathogen of zoonotic significance; its pathogenic potential, adhesions, transmission and control. Indian J Comp Microbiol Immunol Infect Dis 20: 79-90.

26. Corbel MJ (2006) Brucellosis in humans and animals. World Health Organization in collaboration with the Food and Agriculture Organization of the United Nations and World Organization for Animal Health. Geneva.

27. Bhardwaj M, Singh BR, Murugan MS, Prasannavadhana, Dubey S (2015) Emergence of Carbapenemase Producing Pathogens in Animals. Pharm Anal Acta 6: 379 .

28. Singh BR (2010) Antimicrobial Drug uses by Veterinarians in Equine Clinical Cases in India. Res J Vet Sci 3: 165-178.

29. Singh BR, Singh RK, Singh V (2014) Carriage of multiple drug resistant bacteria in vagina of apparently healthy swamp buffaloes in Nagaland. Adv Anim Vet Sci 2: 292-295.

30. Singh BR (2014) Multiple-herbal-antimicrobial-resistance (MHAR) in microbes of animals, birds, fish, food, lizard and water origin. In: Proceedings of International conference and 28th Annual convention of IAVMI-2014 on Challenges and opportunities in animal health at the face of globalization and climate change, Department of Veterinary Microbiology and Immunology, DUVASU, Mathura, India 1: 26-29.

31. Singh BR, Singh RK, Singh $\vee$ (2015) Aerobic mesophilic bacterial flora of vagina of healthy mithun (Bos frontalis). J Genital Sys Disord 3: 1-7.

32. Mukherjee P, Ramamurthy T, Mitra U, Mukhopadhyay AK (2014) Emergence of high-level azithromycin resistance in Campylobacter jejuni isolates from paediatric diarrhoea patients in Kolkata, India. Antimicrob Ag Chemother 58 4248.

33. Verma AK, Singh BR, Sinha D K, Chandra M, Agrawal RK, et al. (2007) Salmonellosis in Apparently healthy dogs. J Vet Pub HIth 9: 37-39.

34. Laxminarayan R (2010) Antibiotic resistance: a challenge to public health in India. Global Antibiotic Resistance Partnership 10: 226-236.

35. Stephen J1 (2001) Pathogenesis of infectious diarrhea. See comment in PubMed Commons below Can J Gastroenterol 15: 669-683.

36. Wagenlehner FM1, Wullt B, Perletti G (2011) Antimicrobials in urogenita infections. See comment in PubMed Commons below Int J Antimicrob Agents 38 Suppl: 3-10.

37. Singh BR, Singh AK, Sharma S, Reyaz M, Kumar S, et al. (2014) Testing of FMD Vaccine (intended to be used under FMD-CP of Govt of India) at CCS NIAH, Baghpat (UP) India.

38. Mabvuure NT, Klimach S, Eisner M, Rodrigues JN (2015) An audit of best evidence topic reviews in the International Journal of Surgery. See comment in PubMed Commons below Int J Surg 17: 54-59.

Citation: Singh BR, Agrawal R, Prasanna Vadhana, Bhardwaj M, Dubey S (2015) Antimicrobial Activity of Citronella Essential Oil on Antimicrobial Drug Resistant Bacteria from Veterinary Clinical Cases. Clin Med Biochem Open Access 1: 106. doi:10.4172/2471-2663.1000106 